NEWS

\title{
Western states launch carbon scheme
}

If the federal government doesn't get its act together on carbon trading, individual US states will come together to decide policy instead. That was the clear message when the governors of five western states - Washington, Oregon, California, Arizona and New Mexico - signed an agreement on 26 February to create their own carbon cap-and-trade programme. The move parallels a similar scheme developed by northeastern states; together the two regions account for nearly a quarter of US carbon emissions.

As California's governor Arnold Schwarzenegger puts it: "This agreement shows the power of states to lead our nation in addressing climate change."

The western group is moving relatively quickly. It also intends to go further than the northeastern scheme, the ten-state Regional Greenhouse Gas Initiative (RGGI), which focuses on the electricity industry. "Within 18 months, we want to return with a design for a multi-sector, market-based system," says Dan Skopec, an undersecretary at the California Environmental Protection Agency. Each state will set its own caps.

California was already devising a market approach to managing emissions. But some worried that regulated companies would leave the state to avoid being capped. The new scheme, the Western Regional Climate Action Initiative (WRCAI), has nearly all the states that border California on board, so such leakage seems unlikely. The exception is Nevada, but Skopec says he still hopes it will join.

In the electricity sector, the WRCAI may

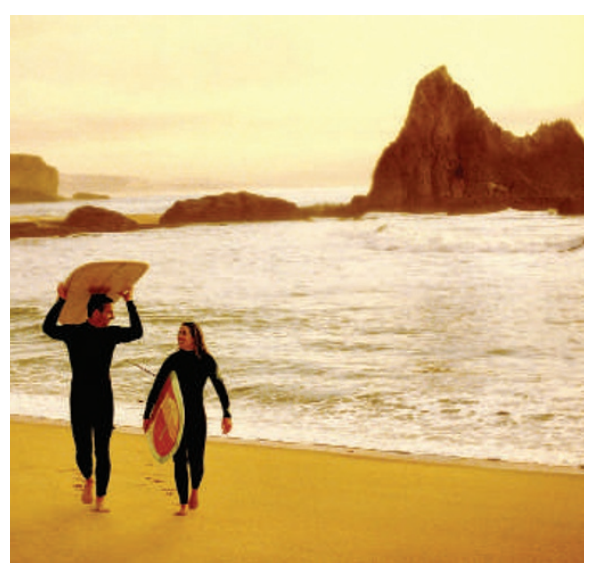

The United States is seeing a wave of regional climate initiatives. operate differently to RGGI. Starting in 2009, RGGI will cap companies that generate energy, and they must then either ramp down operations, invest in cleaner technologies, or buy offsets to meet their targets. California had favoured the idea of capping the distributors who sell electricity to the customer, to cover all electricity sold in the region no matter where it was produced. But with neighbouring states on board as well, the scheme may stick to capping the generators.

On a national level, the Democratic Congress is holding hearings and proposing bills on emissions at a breakneck pace, but even with the new initiative, the crucial 60 votes needed in the Senate look unlikely to be found. As such schemes become more popular, however, pressure will mount on the federal government to come up with a cap-and-trade scheme or risk having states do it for them.

According to the Pew Center on Global Climate Change, if all the states in the two regional schemes counted as a country they would be the world's fourth largest emitter. "At some point you have critical mass. At some point you have enough of a system that it just becomes the standard, and states sign on voluntarily

\section{Scriptural violence can foster aggression}

There once was a man and his concubine from the Israeli tribe of Ephraim who were travelling in the land of Benjamin, another Israeli tribe. As the couple dined in the city of Gibeah, a mob assembled outside and pounded on the door. The mob captured the concubine, then raped and beat her to death. The man collected her corpse the next day and travelled home. The other tribes of Israel were outraged at the crime, assembled an army and razed several Benjamite cities, killing every man, woman, child and animal they could.

Around 500 students recently read a version of this story, which is based on a passage from the Old Testament, as part of a psychological study. For half of the participants the tale contained an additional passage: when the man returned home, his tribe prayed to
God and asked what they should do. God commanded the tribe to "take arms against their brothers and chasten them before the Lord".

After reading the story, the students participated in another exercise intended to measure aggression. About half of the study participants came from Brigham Young University, a religious university in Provo, Utah, and almost all were members of the Church of Jesus Christ of Latter-Day Saints. The other half came from the Free University in Amsterdam. Only $50 \%$ of the Dutch group believed in God and $27 \%$ in the Bible. But for both groups - whether the students were based in the Netherlands or the United States, and believed in God or not - the trend was the same: those who were told that God had sanctioned the violence against the Israelite were more likely to act aggressively in the subsequent exercise.

The study is indicative of a growing interest among psychologists and sociologists in the origins of religious violence. That subject was taboo until recently for many psychologists, and past research tended to focus on the role of religion

\section{"If violence is presented} as the authoritative voice of God, it can increase the possibility of more violence."

in psychological healing. But heightening concern about religious terrorism has pushed negative uses of religion to the forefront. "People often use God as a justification for committing violent acts," says Brad
Bushman, a social psychologist at the University of Michigan in Ann Arbor and lead author of the study. "And that just bothers me, I guess."

The results of Bushman's study, to be published in the March issue of Psychological Science, do not indicate that religious people are more aggressive than nonreligious people (B. J. Bushman et al. Psychol. Sci. 18, 204-207; 2007). Furthermore, the story us ed was an isolated example of scriptural violence taken out of context, and thus does not reflect the experience of reading the Bible as a whole. But it does suggest that selective exposure to violent passages in a scriptural canon can promote aggression.

That response probably reflects a long-standing finding in psychology that people respond more aggressively to a depiction of 


\section{REGULATING GREENHOUSE GASES}

A new initiative to control carbon dioxide emissions in the US west complements an earlier initiative in the east. Here's a look at the states that are participating, and the percentage of total US carbon emissions they make up.

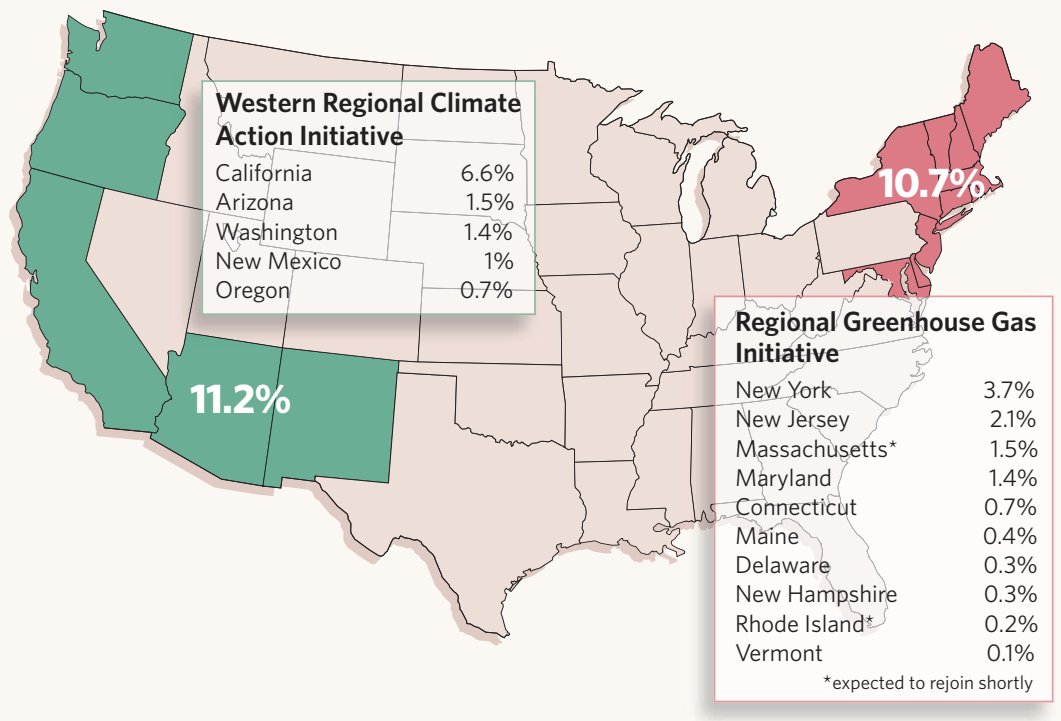

or the federal government will just adopt it," says Véronique Bugnion, the Washington DCbased director of research for emissions trading consultants Point Carbon.

To help reach that critical mass, the two schemes may link up, and perhaps even join forces with the European Union (EU) Emission Trading Scheme. "The bigger the market, the more cost-effective reductions are available," says John Larsen, a research analyst at the
INTERNATIONAL

POLAR YEAR

See pages 126-135\& online. www.nature.com/news/ infocus/polarresearch. html

World Resources Institute, an environmental group in Washington DC. "It will be interesting to see how they move forward and who they talk to."

Skopec says that California is already moving towards this, but there are some potential hitches. One problem is the different way the schemes are regulated. For example, if more states joined the two US groups, electricity generated in a RGGI state and exported to a state in the WRCAI, which may regulate distributors, could potentially be counted twice.

And differences in how tough the caps are could set up a lopsided situation in which companies in low-cap areas keep buying credits from high-cap areas. "You have to link equivalents," says Bugnion. "If one system is more stringent than another, the credits will only flow one way." There's also the problem that the EU trading scheme operates under the aegis of the Kyoto Protocol, a treaty that the United States hasn't ratified and that individual US states cannot join.

A looser form of linking may be easier. The RGGI plan already allows the purchase of offset credits from projects certified by the Clean Development Mechanism, an apparatus of the Kyoto Protocol. A shared pool of available offsets can bring prices in the separate markets closer together, even if they aren't linked directly.

Emma Marris

violence that they feel is justified, says Robert Ridge, a social psychologist at Brigham Young University and a co-author of the study.

Sociologist Mark Juergensmeyer of the University of California, Santa Barbara, says his research has also pointed to the motivational power of scriptural violence, but that the context of the message is key. "If violence is presented as the authoritative voice of God, it can increase the possibility of more violence," says Juergensmeyer. "But everything depends on how it is presented." The same passage placed in a non-threatening, historical context might not promote aggression, he argues.

Nevertheless, when scriptural violence is used to promote hostility, it is extremely effective, Juergensmeyer adds. Invoking religious justification allows a political leader to believe in promises of immortality and spiritual rewards that can be powerful motivators. "Religion is not the problem," he says. "But it can make a secular problem worse."

People often choose to ignore the violent side to religion, says John Hall, a sociologist at the University of California, Davis, and they tend to dismiss those who commit religiously inspired violence as members of the fringe. "There are built-in cultural lenses that we use to dissociate religion from violence," he says. "When we see religious movements that are prophetically inspired and engaged in violence, there's a cultural tendency to say 'oh, they're not really religious'."

That view represents a misleading, selective interpretation of most religious canons, agrees theologian Hector Avalos of lowa State University in Ames. "People who choose the violent interpretation are no less arbitrary than those who choose the peaceful

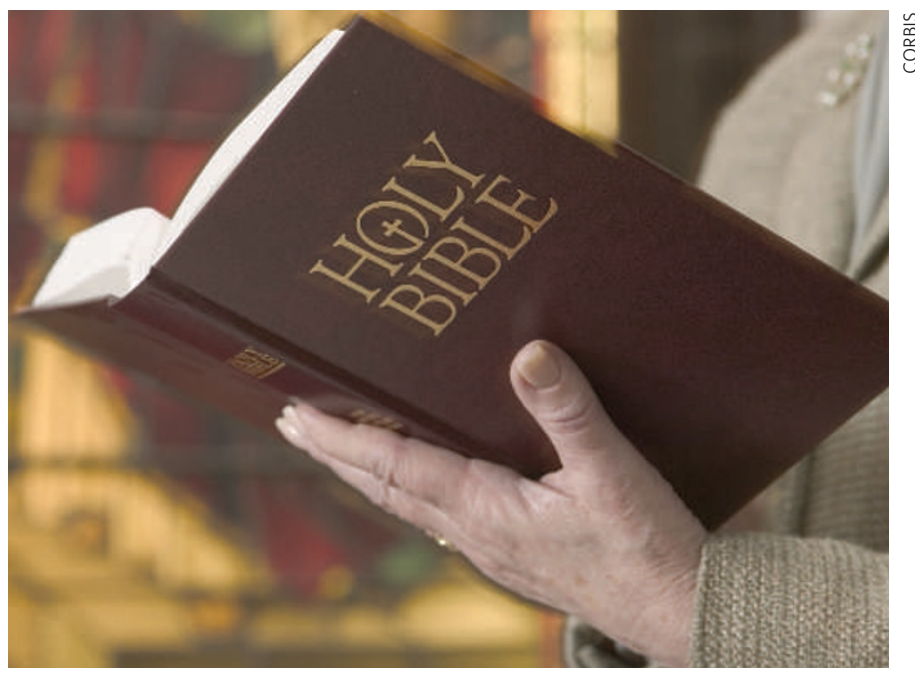

God's sanction can be a motivator for aggression.

one," he says. Avalos has proposed a radical solution to theologically inspired violence - cut the violent passages out of the scripture.

It's a wildly controversial idea that ought not to be, he says, because spiritual leaders effectively do that on a regular basis. "A lot of churches have a series of passages that they read during the year," says Avalos. "And usually they don't choose the passages involving genocide."

Heidi Ledford 